\title{
Café y palabras. Las voces de las mujeres que cruzan fronteras
}

\section{Coffee and words. The voices of women who cross borders}

\author{
Leticia BRAVO SÁENZ \\ Consejo de la Juventud de la Rioja (España) \\ leticia988@hotmail.com \\ Neus CAPARRós CiVERA \\ Universida de La Rioja (España) \\ caparros@uniroja.es
}

Recibido: 04/06/2014

Revisado: 04/07/2014

Aceptado: 01/10/2015

Disponible on line: $25 / 11 / 2015$

\begin{abstract}
Resumen
En la trayectoria de vida de una mujer inmigrante pueden distinguirse principalmente dos tipos de fronteras: las primeras, y más «sencillas» de sortear, son los límites físicos entre dos Estados; las segundas, en cambio, adoptan diversas formas, como: crisis culturales, prejuicios o sentimientos de melancolía, y desafortunadamente se antojan a veces insalvables.

El ciclo de tertulias «Café y palabras», la experiencia que ha dado origen a este estudio, ha sido desarrollado en la Asociación YMCA Logroño, como parte de la intervención de un proyecto más amplio, y ha tenido como protagonistas a doce mujeres inmigrantes de distintas nacionalidades, a quienes se dio voz para expresar sus opiniones respecto a temas muy variados.

Los objetivos de esta implementación perseguían, a través de un clima distendido que aunara la devoción culinaria con la práctica del castellano, una deseada integración en la sociedad mediante el reconocimiento de las demás y de una misma, como persona útil y miembro activo del grupo. El intento de engranar dichos propósitos no sólo ha alcanzado resultados fructíferos, sino que ha puesto de manifiesto que la convivencia en interculturalidad nace de un esfuerzo compartido.

Palabras clave: multiculturalidad, empoderamiento, género, inmigración, trabajo social grupal.
\end{abstract}

\begin{abstract}
Within the path that immigrant women's lives take, one may distinguish two main types of borders. The first and most «simple» to overcome are the physical boundaries between two states. The second sort, meanwhile, takes various forms, such as cultural crisis, prejudices and feelings of sadness. Unfortunately, these sometimes seem insurmountable.

The «coffee and words» series of social gatherings, the experience that gave rise to this study, was developed by the Logroño YMCA as part of the intervention of a broader project. Its protagonists were twelve women immigrants of different nationalities, who were given a forum in which to express their opinions on a very wide range of subjects.

The object of the initiative was to achieve integration into society via recognition of the other and oneself as a useful person and an active member of the group, through a relaxed atmosphere that combined culinary passion and practicing Spanish. The attempt to achieve these goals delivered successful results and also demonstrated that coexistence based on interculturality is the result of a shared effort.
\end{abstract}

Keywords: Multiculturalism, empowerment, gender, immigration, group social work.

Referencia normalizada: Brazo Saénz, L., y Caparrós Civera, N. (2015): «Café y palabras. Las voces de las mujeres que cruzan fronteras». Cuadernos de Trabajo Social, 28(2): 225-234.

Sumario: Introducción. 1. Marco teórico: Mirando lo que no se ve. 2. Diseño del proyecto: Cómo nació y creció la idea. 3. Desarrollo del proyecto: la alegría tiene nombre de café. 4. Resultados y evaluación: el cierre. 5. Conclusiones. 6. Referencias bibliográficas.

\section{Introducción ${ }^{1}$}

Llenar una maleta, dejar atrás tu casa, tu familia y empezar desde cero en un país extranjero son hechos comunes en los tiempos que corren. ¿Y qué ocurre después? Los medios de comunicación visibilizan a menudo la situación de las per-

${ }^{1}$ Los nombres que aparecen en todo el artículo no se corresponden con la realidad, han sido sustituidos para mantener la privacidad y anonimato de las participantes 
sonas que encuentran el triunfo en esta nueva etapa, pero muy pocos espacios dan voz a aquellas otras que siguen luchando día tras día. El estudio que se presenta es fruto de la experiencia del ciclo de tertulias Café y palabras, realizadas con un grupo de mujeres inmigrantes, que participan en las clases de castellano de la Asociación YMCA.

La implementación de dicha experiencia, que forma parte de un proyecto más amplio, sucede a una fase de investigación en la que, por medio de una doble metodología cuantitativa y cualitativa, se llevó a cabo la recogida de información que motiva este texto. Siguiendo el método básico de Trabajo Social, a lo largo de estas páginas se parte del estudio de la situación-problema, que consiste en un análisis genérico sobre la situación socio-personal de las mujeres extranjeras que residen en España; posteriormente, tras la emisión de un diagnóstico por el que se establece la necesidad de buscar y diversificar espacios de intercambio entre ellas, se desciende a la sistematización concreta de las seis tertulias, y a la evaluación de sus resultados y principales conclusiones con un enfoque de interés principalmente cualitativo, que responde a la evolución interior de las participantes.

\section{Marco teórico: mirando lo que no se ve}

Actualmente, la población inmigrante en España, en especial las mujeres y con intensidad las que proceden de países extracomunitarios, se encuentra con un amplio número de barreras que cruzan, a menudo por iniciativa y en otras ocasiones por imposición. La razón de este «salto» germina en la existencia de fronteras más difíciles de franquear que las barreras geográficas que atravesaron en su día con mayor o menor éxito, dejando atrás no sin dolor una historia con nombre propio.

Las distancias físicas son grandes pero no prohibitivas y los aeropuertos, principalmente el de Barajas, se dibujan como el escenario más importante de desembarco de la inmigración irregular en nuestro país. La otra cara de la moneda la constituyen los conocidos popularmente como «espaldas mojadas» hombres y mujeres procedentes de Marruecos, Argelia, Asia y, en su mayoría, de países subsaharianos que arriban a las costas canarias y andaluzas por vía marítima y de forma clandestina. Se estima que estos viajeros pagan alrededor de 1.000 euros por subir a una embarcación y enfrentarse a una de las áre- as marítimas más peligrosas del mundo, lo que ha convertido al Estrecho en una de las mayores fosas comunes del planeta.

Las razones de la migración cambian de un país a otro, no son las mismas en Rusia que en el Magreb, el África sub-sahariana o América Latina. Sin embargo, todos estos puntos del mapa comparten una situación de crisis política, social y/o económica cuasi permanente durante una o varias generaciones, que sucumben pese a los miedos de la recesión europea occidental, también reciente, a la información de los paisajes suscitados por los medios de comunicación de masas, los espacios publicitarios y las redes sociales que se van formando en torno a la propia emigración (Pérez Grande, 2008, p. 153)

En los últimos tiempos asistimos a una mayor visibilidad social y política y a un incremento significativo del número de mujeres en los procesos migratorios, un fenómeno que se ha denominado «feminización de la inmigración». Los profesores Giró y Fernández Sáenz de Pipaón (2004) revelan que los principales motivos de la llegada a Logroño de estas mujeres responden a relaciones familiares y de amistad, al ánimo de reunirse con los suyos y recuperar la identidad de grupo.

Igualmente, el paro, la pobreza, la violencia étnica o de género son factores que influyen en la decisión de partir; pero también existen cada vez más mujeres autónomas que recorren kilómetros motivadas por razones de mejora personal, como la profundización en sus estudios o profesiones, los deseos de conocer Europa o sentirse más libres, rompiendo de alguna forma con la imagen de mujer inmigrante pobre, ignorante $\mathrm{y}$ analfabeta. El colectivo es diverso en pautas culturales, creencias, pertenencias éticas, países de origen y color de la piel; y todo ello va a influir de manera diferente en sus vivencias, así como en sus percepciones cuando entran en contacto con el país receptor, ya que será éste el que marque las reglas del juego (El Hadri y Navarro, 2001, p. 2).

Como consecuencia, podemos aventurarnos a decir que la cultura constituye uno de los muros invisibles más altos, que en ocasiones se tornan inespugnables (Goicoechea; Clavo, 2012, p. 39).

Giró y Fernández (2004) de nuevo coinciden en afirmar que las mujeres inmigrantes que residen en España sienten sobre sus hombros la responsabilidad de establecer un puente entre am- 
bas culturas. En la mayoría de los colectivos, son las encargadas de mantener y transmitir las propias tradiciones a sus hijos y nietos, al mismo tiempo que posibilitan el acceso a unas nuevas, en un marco familiar en el que paradójicamente su papel no suele reconocerse en público.

La historia más reciente también constata que las mujeres inmigrantes son más pragmáticas que los hombres en su adaptación a los diferentes modos de vida y opiniones, de manera que se muestran más tolerantes ante la pluralidad de valores sin sentirse amenazadas; manifiestan mayor perseverancia y paciencia en los largos procesos de formación y tienen mayores aptitudes para orientarse y dominar la práctica cotidiana.

Igualmente podemos añadir que en el devenir migratorio estas mujeres buscarán, en las sociedades de destino una identificación colectiva, en primer lugar entre los iguales. En cambio, pese a la tendencia general a una actitud permeable, su doble condición de mujeres inmigrantes les condena inevitablemente, en muchos casos, a la invisibilidad y pérdida de espacio personal.

No son pocas las voces que vinculan en parte dichas circunstancias a la reglamentación estatal en materia de inmigración. Los planes autonómicos que acompañan a la Ley Orgánica 4/2000, de 11 de enero, sobre Derechos y Libertades de los Extranjeros en España y su Integración Social, se encuentran caducos en algunas comunidades, como La Rioja, donde este documento prescribió en diciembre de 2012; o son directamente inexistentes en otras, por ejemplo, en Galicia; y en pocos casos han sido diseñadas desde una auténtica perspectiva de género. Además Torres (2002) pone en evidencia las limitaciones de un modelo de integración basado exclusivamente en la inserción laboral de las personas inmigrantes, la seguridad jurídico-administrativa y un trato no discriminatorio, que se aleja de la igualdad de condiciones, derechos y deberes de los nacionales.

Todo ello en un marco de inestabilidad de la citada «ley de extranjería», que contempla entre sus medidas más recientes la exclusión de «los extranjeros no registrados ni autorizados como residentes en España» (art. 12) de la cobertura gratuita al Sistema Nacional de Salud. Esta reforma, que conlleva la ruptura del principio de sanidad universal y gratuita para todas las personas, muchos profesionales del ámbito de la medicina y la ayuda la consideran como un distan- ciamiento de la equivalencia de oportunidades y, por lo tanto, del tan anhelado crisol de la interculturalidad.

La situación de soledad puede agravarse, según la procedencia de las mujeres, ya que mientras algunas tienen un férreo control, otras desarrollan nuevos espacios de relación, reinventando modelos de ocio. La tónica habitual es que las mujeres originarias del Este de Europa, albergan costumbres y hábitos sociales comunes a los de los españoles, presenten una actitud abierta y una integración rápida. En cambio, las mujeres inmigrantes extracomunitarias sufren en general una gran falta de reconocimiento social y numerosas dificultades para participar en la sociedad de destino, que varían de unos colectivos a otros. Por consiguiente, podemos afirmar que el lugar de procedencia distingue las actividades sociales $\mathrm{y}$, en concreto, los espacios.

Otras variables significativas que diferencian la vida social y la pauta de integración de estas mujeres son la edad, el idioma y, en el caso de algunas de ellas, el tipo de trabajo. La juventud multiplica la libertad, facilita la adaptación al cambio y se encuentra ligada a la vida estudiantil $u$ otras actividades formativas que incrementan el desarrollo de las relaciones sociales.

El idioma, por su parte, constituye la principal herramienta comunicativa para favorecer la integración. Es indiscutible que aquellas mujeres que a su llegada carecen de conocimiento o fluidez del castellano se encuentran más cómodas relacionándose con personas que hablan su lengua materna. Esta variable, especialmente relevante entre las mujeres árabes y chinas y en quienes poseen una lengua radicalmente distinta al castellano, puede conducir nuevamente a un modelo endogámico y en ocasiones, a un círculo vicioso entre el idioma y la vida social.

El tipo de empleos que las mujeres inmigrantes realizan es otro elemento diferenciador en la adopción de modelos de integración. Se ocupan principalmente de tareas que no exigen permiso de trabajo ni inscripción en el Régimen General de la Seguridad Social, pero contribuyen al sostenimiento del Estado de bienestar y la solución de problemas comunitarios acuciantes. De este modo, los horarios de aquellas que trabajan como internas en un domicilio, o en la hostelería, son un obstáculo para coincidir con los de su círculo de amistades y parientes, impidiéndoles una vida social placentera. 
Con el fin de entender la capacidad de las mujeres inmigrantes para adaptarse a un contexto distinto a su cultura, es importante delimitar este concepto, notablemente amplio y muy difuso. ¿Qué elementos encierra? ¿Cuáles son sus características? Para la elaboración de este estudio se ha tomado como partida la definición de cultura de Tylor (Pérez González, 2007, p. 116) que la concibe como «aquel todo complejo que incluye el conocimiento, las creencias, el arte, la moral, el derecho, las costumbres y cualesquiera otros hábitos y capacidades adquiridos por el hombre en cuanto miembro de la sociedad». O tal y como apunta Harris (1981), cultura como las pautas de conducta y pensamiento aprendidas y compartidas que son características de un grupo social, (p. 594) refiriéndose al estilo de vida total, socialmente adquirido, de un grupo de personas, que incluye los modos pautados y recurrentes de pensar, sentir y actuar (p. 123)

De esta manera, la cultura es la expresión de todos los elementos que nos identifican y no se encuentra necesariamente marcada por el lugar de origen, puesto que es permeable y puede adaptarse a las circunstancias vitales.

Entre los componentes culturales, las creencias religiosas se perfilan como una de las incipientes razones de distanciamiento, racismo y conflicto entre culturas. Las creencias religiosas constituyen el núcleo del sistema de valores, ideas y valores que orientan y estructuran la acción humana. En este sentido la religión se entiende como un conjunto de ideas que han surgido como parte de la cultura, como parte de esas propias ideas humanas. (Beltrán, 2007, p. 77)

Un aspecto que conocen de primera mano las mujeres que profesan el Islam, a quienes el velo expone como personas privadas de libertad a los ojos de gran parte de la población del país receptor. Esta afirmación de que muchas veces se realiza por desconocimiento de la doctrina del Corán, ha sido foco de múltiples debates y objeto de sensacionalismos. Para ellas, la voluntad de Dios requiere que la mujer se cubra para distinguirse de la gente, ser identificada como una musulmana respetable y devota y protegerse de las miradas, comentarios e insolencias de algunos hombres. Más allá de un simple trozo de tela, el velo refleja la moral interior y los valores inviolables de la identidad musulmana, como la castidad y la rectitud. Por lo tanto, se trata de un signo de protección y reafirmación cultural, no de sometimiento.

En cambio Miguel Pajares, experto en temas migratorios, declara que «el velo está originalmente relacionado con la tradición que impedía a las chicas elegir por sí mismas la pareja para el matrimonio; su invisibilidad, cubriéndose lo más posible, estaba en consonancia con el hecho de que no debían atraer la atención de ningún chico, porque era la familia la que se encargaría de emparejarlas» (El País, 2004, p. 10). En esta misma línea suenan las voces que conciben el velo como símbolo de discriminación de la mujer y sumisión a su marido, aunque no del modo vejatorio en el que se entiende la violencia física, psicológica o sexual.

En nuestra vecina Francia, sin ir más lejos, la Circular Bayrou de 20 de septiembre de 1994 se oponía a que las niñas llevasen a clase la cabeza cubierta, por considerar el hiyab como un «signo ostentoso de diferenciación que crea separación entre los jóvenes». En el contexto de una sociedad laica en la que la fe era y sigue siendo, un asunto privado, dicha prohibición no sólo creó más desarmonía en el ámbito escolar, sino que reforzó el simbolismo identitario del velo y evidenció la necesidad de los países europeos de afrontar «el aumento de población inmigrante procedente de países con tradiciones religiosas que hasta el momento no tenían tanta fuerza» (Innerarity, 2005, p. 143).

Igualmente, este discurso recuerda a otras muchas creencias y tradiciones islámicas que el mundo occidental mira con recelo, por considerarlas contrarias a la dignidad femenina. Entre ellas, el concierto de los matrimonios, la dote, la poligamia y, tal vez la más irritante, el repudio o talâq, que en árabe significa «librarse de ataduras», y se considera que constituye uno de los privilegios del hombre musulmán.

Por otra parte, aunque no todos los componentes de índole cultural originan tanta controversia como la fe, cualquier diferencia entre las costumbres que comprenda el estilo de vida en el país de origen y las de la sociedad de acogida puede causar también aislamiento o desazón.

Los hábitos alimenticios, por ejemplo, constituyen un factor que se vincula doblemente al proceso migratorio, por su carácter nutricional, y al mismo tiempo, sentimental: los recién llegados, y en especial las mujeres que se encargan de 
las tareas domésticas, dudan sobre qué comprar, el nombre y las propiedades de los nuevos productos o la forma de cocinarlos.

En conclusión, puede decirse que en el proceso migratorio de una mujer existen innumerables fronteras. Algunas son visibles, como el idioma o las que delimitan el tránsito entre dos Estados, y son relativamente sencillas de cruzar en comparación con aquellas otras invisibles, pero reales que pueden llegar a erigirse como auténticas murallas. Por mencionar algunas de ellas: la cultura, la ley, las creencias religiosas, la nostalgia de los seres queridos, las costumbres, los hábitos sociales y alimenticios o los estereotipos.

La conocida como «guerra del velo» en Francia, a la que se ha aludido anteriormente, cuestionó la eficacia del modelo tradicional de asimilación que supone «una total identificación del inmigrante con el nuevo universo cultural que le acoge y el olvido de sus referencias, para introducirse de la manera más completa en su nuevo paisaje» (Ramadan, 1994, citado en Innerarity, 2005 , p. 149). Por el contrario, el derecho de los grupos étnicos y las minorías religiosas a conservar y expresar sus tradiciones ni es caduco ni debe ser cuestionado, sino que goza de carácter permanente, sin que ello suponga un obstáculo para su éxito en las instituciones de la sociedad dominante. Los grupos étnicos o las minorías religiosas desarrollan lo que conocemos como identidad colectiva, cuando el individuo se identifica con otros individuos afectados por las mismas circunstancias, debido a que a través de su nueva identidad podrá opta a conseguir determinados beneficios, porque existe un interés compartido. (Del Olmo, 2003, p. 34)

Por lo tanto, la integración no es solamente una cuestión de esfuerzo por parte de las mujeres (o igualmente hombres) que llegan a un país, sino una vuelta al equilibrio, una inquietud de aproximación y un crecimiento en la diversidad de todas las personas que componen la nueva sociedad. Por ende, sería necesario tender más puentes para vencer los sentimientos mutuos de miedo, desorientación y desconfianza, que paralizan y dificultan el acceso al aprendizaje de la convivencia.

\section{Diseño del proyecto: Cómo nació y creció la idea}

Esta iniciativa surgió como resultado de las necesidades detectadas en las participantes de la Asociación $\mathrm{YMCA}^{2}$. Todas las participantes eran extranjeras de origen. El Proyecto de investigación «Mujeres inmigrantes: promoción de las relaciones sociales a través de la Educación y el Ocio», realizado entre 2011 y 2012, en el que se realizaron entrevistas semi-estructuradas, a alumnas de castellano de nivel avanzado, surgieron las demandas de actividades relacionadas con la cocina y creación de más ocasiones en las que poder expresarse. Así fue como surgió Café y palabras, un programa de tertulias que persiguen la finalidad de crear espacios de encuentro distendidos y con tintes culinarios entre las mujeres inmigrantes, ofreciendo un canal de expresión de sus intereses e inquietudes, así como una herramienta lúdica para practicar el castellano.

Asimismo se propone que una o dos participantes se encarguen semanalmente de preparar un plato típico de la gastronomía de su país, para acompañar la conversación y explicar a sus compañeras los ingredientes, la elaboración, la ocasión en que se degusta, etcétera. Se caracteriza, por lo tanto, por tratarse de una metodología libre, participativa y no directiva.

Se trata de un grupo heterogéneo en edad, puesto que los años de las mujeres oscilan entre 23 y 50 . En cambio, otros aspectos son relativamente homogéneos como: la procedencia, las creencias religiosas, la circunstancia migratoria y la situación laboral. Respecto a los países de origen, ocho de ellas proceden de Marruecos y las cuatro restantes de países distintos: Argelia, Gambia, Pakistán y Rusia. Como consecuencia, diez son naturales del continente africano (en concreto, nueve de la región de Magreb y una de África sub-sahariana), una de Asia y una de Europa oriental. En cuanto a las creencias religiosas, once profesan la religión islámica, mientras que únicamente una es católica ortodoxa.

Todas llegaron a España en compañía de sus esposos hace cuatro años como media, en busca de una oportunidad laboral o una mejora en la calidad de vida. Superaron los estudios primarios en sus países — en tres de los casos, también

2 Young Men's Christian Asociation, de Logroño. Asociación fundada en Londres en 1844, declarada de utilidad pública y actualmente sin imposición religiosa, cuyo objetivo principal es contribuir a mejorar la vida de niños y jóvenes y sus familias. 
secundarios y de formación profesional, y se encuentran actualmente en situación de desempleo-. Salvo en YMCA, no forman parte de otra asociación de ningún tipo y se ocupan principalmente de las tareas domésticas y el cuidado de sus hijos.

Surge la iniciativa para crear un espacio de intercambio desinteresado entre personas con las mismas inquietudes, con similares situaciones y necesidades, las de relacionarse con el entorno, de abrirse en una nueva realidad y una manera de empezar a hacerlo es con sus iguales, mujeres extranjeras procedentes de otros países, con culturas diferentes de las del país de recepción. La relación con las autóctonas vendrá después, en unas segundas tertulias, en unos segundos cafés, habiendo aprendido en los primeros una serie de hábitos y maneras de relacionarse y de abrirse al resto de la comunidad.

\section{Desarrollo del proyecto: la alegría tiene nombre de café}

Impulsar la integración social de las mujeres inmigrantes y crear un espacio de encuentro y ocio entre estas mujeres eran los objetivos principales que movilizaron la puesta en marcha de este proyecto grupal. Concretamente y para cada una de las sesiones programadas: ofrecer canales de expresión de los intereses e inquietudes de las mujeres inmigrantes; practicar y mejorar el castellano de forma lúdica y amena; favorecer el intercambio y el enriquecimiento cultural; y fortalecer la autonomía y la autoestima mediante un tiempo de dedicación personal. Las mujeres participantes debían sentirse integrantes de la sociedad en la que estaban viviendo, con nuevos lazos sociales más allá de sus propios núcleos étnicos y de convivencia habituales, así como ampliando el tiempo y el espacio del esparcimiento personal. Surgen así las diferentes sesiones amenizadas con platos típicos de cada una de las integrantes y con el colorido que desprenden sus atuendos.

Y así, juntando un par de mesas en el aula de castellano, entre porciones del bizcocho de limón, empieza la primera reunión. Todas conocen la receta del postre que ha elaborado la dinamizadora y es la marroquí Aaminah quien se atreve a explicarla a las demás. Leila, la única participante de Pakistán, se ofrece voluntariamente a preparar un plato típico de su gastronomía para la siguiente sesión.
La dinámica, la maleta mágica, sirve para romper el hielo y comentar sus prioridades actuales en la vida. Entre todas aportan ideas muy variadas que dan pie a un diálogo enriquecedor sobre libros, moda, religión, familia, etc. Las mujeres de Marruecos se muestran especialmente arraigadas a su cultura, repitiendo en varias ocasiones, el Corán y los caftanes (vestidos femeninos tradicionales del país) como objetos imprescindibles para ellas. Además, por su grado de complicidad, puede apreciarse también que algunas se conocen y mantienen relación fuera de las aulas.

La segunda tertulia trae consigo una sorpresa: se unen a participar otras seis compañeras, cuatro de Marruecos y dos de Pakistán.

La visualización del corto de animación - Parcialmente nublado - sirve como pretexto para conversar sobre la amistad, un tema que desde el primer momento les atrapa. Las participantes musulmanas coinciden en que el Islam solamente permite que las mujeres tengan amigas y los hombres amigos. Hablar por teléfono, pasear y tomar café o té en casa son las actividades que ellas realizan con sus amigas. Cuentan que no pueden ir con ellas a una cafeteríaporque «no está bien visto» y supondría una falta de respeto a Dios. Pero sí pueden ir con sus respectivos maridos.

Por su parte Irina, que es de Rusia, cuenta que en su país los hombres y las mujeres pueden ser amigos, pero el ámbito de diversión es más privado. Suelen ver películas, tomar café o celebrar fiestas en las casas, no tanto en espacios comunes, como el cine, cafeterías y discotecas.

A medida que transcurren las reuniones la evolución es muy positiva en todos los sentidos. Los platos, por ejemplo, son cada día más elaborados: las mujeres marroquíes cocinan manjares que degustan en ocasiones especiales, como bodas o cumpleaños.

Igualmente, la implicación de las participantes crece en cada tertulia y las palabras fluyen de manera natural y espontánea. Ayudan con entusiasmo a la dinamizadora a preparar y recoger el aula y se intercambian de manera espontánea las recetas de los platos. A veces las horas se antojan escasas y muchas ideas se quedan en el tintero.

Los temas también se modifican en función de las circunstancias o demandas de las participantes. Durante la tercera tertulia, que se centra 
en el Día Internacional de la Mujer, comienza a visibilizarse una mayor comodidad en la posición y la postura corporal. Se sientan aleatoriamente, no siempre al lado de sus paisanas, y muestran una actitud más relajada. Todas están de acuerdo en que las mujeres tienen los mismos derechos que los hombres y creen que no existen profesiones prohibidas para el sexo femenino. Asimismo, coinciden en que las tareas del hogar son responsabilidad compartida entre hombres y mujeres, aunque la mayoría confiesa que sus maridos colaboran en casa sólo si ellas están enfermas o embarazadas.

El amor es el tema estrella en la cuarta tertulia. Hablar de ello les apasiona, les arranca sonrisas sinceras y en ocasiones, les ruboriza. Lidett, de Gambia, opina que para ella amar es ser generosa, compartirlo todo con la familia. La marroquí Odele aclara que puede haber muchos tipos de amor: el de pareja, el que siente por su madre, sus hijos, etc. Y en palabras de Aaminah, «para los musulmanes el más importante es el amor a Dios, después a nuestro padre».

Deciden narrar, una por una, sus propias historias de amor. En los relatos de las mujeres de creencia islámica, se repiten algunos denominadores comunes. Casi todas conocieron a sus esposos a una edad temprana, bien porque los hombres se fijaron en ellas y pidieron la mano a su padre; o porque los progenitores de ambos llegaron a un «acuerdo matrimonial». Tras un par de encuentros para tomar café, prepararon una boda rápida. Reconocen que la primera vez que les vieron se encontraban nerviosas y avergonzadas, pero con el tiempo la timidez dejó pasó al amor.

Respecto a su opinión sobre parejas del mismo sexo, las caras de algunas de ellas son enigmáticas, en especial la de Leila, que abre con espanto los ojos y contesta un sonoro ¡no! «Dios hizo al hombre y a la mujer juntos... ipor algo será!», puntualiza Aaminah refiriéndose a la complementariedad de los sexos. «Mejor soltera que con otra mujer», dice Nur, que más tarde explica que en Marruecos no es extraño que una mujer adulta sea soltera. «Para mí está bien. Como en España... es todo igual que aquí», Irina aporta su punto de vista sobre la homosexualidad.

En la quinta tertulia, las mujeres desenmarañan, de forma anónima en trozos de papel, aspectos de la vida que les preocupan. La crisis y la falta de empleo son los temas más repetidos.
Aparecen también preocupaciones personales, como el deseo de no enfadarse tan fácilmente. El momento más emotivo llega al leer el siguiente mensaje: «me gustaría ver a mi mamá y mi familia». Todas confiesan que echan de menos a sus seres queridos y aunque hablan con ellos por teléfono o skype, no pueden abrazarles. Farah es la primera que rompe a llorar. Nur le sigue, contando entre sollozos que cuando su padre murió no pudo ir al funeral.

Entre confesiones y consejos la hora llega a su fin, con el cierre de una idea alentadora: a pesar de los problemas o preocupaciones, es importante mantener una actitud positiva y una expresión amable (Pérez Grande, 2008, p. 157)

Por último, en la sexta tertulia destaca la ausencia de Irina y el tema de conversación brota directamente de las peticiones de las mujeres musulmanas: la religión. Para ellas, el Islam constituye uno de los pilares fundamentales, pero consideran que gran parte de la sociedad occidental mantiene una visión negativa sobre él y les prejuzga. "Algunas mujeres y hombres se han apartado de mí por la calle, sólo por llevar velo... como si les diera asco», comenta Nur con lástima. «Muchas creen que no tenemos pelo», bromea Odele logrando distender el ambiente. La dinamizadora les invita a hablar: «aquí y ahora tenéis la oportunidad de explicaros, el espacio es vuestro».

Aaminah cuenta que el velo es un mandato del Corán, donde se dicta que las mujeres deben taparse para evitar las miradas y comentarios de hombres que no sean sus maridos. «Nosotras lo hacemos por respeto a Dios, que lo ve todo. El Corán pide que nos tapemos más, la cabeza, las manos... por aquí [se señala los tobillos], pero nosotras no cumplimos todo. «Tenemos que llevar ropa ancha. Y no podemos llevar pantalones», añade Leila. «En casa nos quitamos el velo», prosigue Farah, «con nuestro marido nos ponemos cómodas, nos maquillamos, nos ponemos pantalón corto....» [se levanta el bajo del vestido y todas se ríen al unísono].

Las diferencias culturas entre los países islámicos también salen a la luz cuando la dinamizadora pregunta qué ocurre si una mujer soltera se queda embarazada. «Su padre, su madre... su familia le pega cien veces», responde Lidett con decisión. Por su parte, Leila se acerca al cuello el cuchillo con el que han partido la comida y comunica sin palabras que, en Pakistán, la decapi- 
tarían. «Oh, no, no», expresan algunas participantes marroquíes con cara de horror. «Se tienen que casar. Pero si no quieren, la policía les lleva a la cárcel», dice Odele. «Porque un hombre puede estar con cuatro mujeres, pero siempre con esto»», resume Aaminah mostrando su alianza.

Como colofón a la última reunión, la trabajadora social de YMCA propone a las participantes que dirijan una ponencia en el mes de mayo sobre las mujeres en la religión islámica. Algunas aceptan tímidamente. La idea les avergüenza, pero a la vez les entusiasma. De este modo, concluye el ciclo de tertulias «Café y palabras», que no desaparece, solamente se transforma.

\section{Resultados y evaluación: el cierre}

Todo el trabajo ha girado en torno al objetivo grupal de fomentar redes de relación, tanto en el propio núcleo de las participantes como fuera del mismo, al tiempo que perseguía los propósitos individuales de elevar la autoestima y fomentar la expresión de opiniones y sentimientos.

Por ende, para centrar la atención en tales aspectos cualitativos, difíciles de plasmar no obstante, se ha empleado una metodología de evaluación basada principalmente en la lluvia de ideas, mediante la celebración de grupos de intercambio de opinión, y la observación participante, que ha dado lugar a la elaboración de un diario de campo.

En cuanto a la primera técnica, antes de comenzar la tertulia «presente y futuro» la dinamizadora planteó a las participantes, como punto de partida, una serie de preguntas:

¿Qué es para vosotras una tertulia? ¿Habéis participado alguna vez en una experiencia parecida?¿Qué esperáis de estas tertulias? y ¿Sobre qué temas os gustaría hablar?

De las respuestas obtenidas, destaca el hecho de que la mayoría desconocían la noción de una tertulia y nunca antes habían vivido una experiencia similar. De hecho, salvo la asistencia a clases de castellano, era la primera vez que participaban en una actividad en grupo. Se mostraron, por lo tanto, muy reservadas a la hora de hablar sobre sus expectativas de la actividad y proponer temas, otorgando completa libertad a la dinamizadora, «lo que tú quieras estará bien».

Asimismo, en una fecha intermedia al desarrollo de «Café y palabras», tras la celebración de la tercera tertulia, se cuestionó a las participantes sobre la evolución de algunos aspectos:
¿Os han gustado hasta el momento las tertulias? ¿Qué creéis que os aportan? ¿Cambiaríais algo de ellas? ¿Hay algún tema que aún no hayamos tratado sobre el que os gustaría hablar?

Atendiendo a las opiniones que las mujeres expresaron en este momento, se observaba un entusiasmo elevado con las reuniones, de las que declararon que no cambiarían ningún aspecto: «me gusta que un día hablemos sobre nosotras», afirmó Nur; «sí, hablamos y aprendemos más de todo... de tu país, de mi país», corroboró Aaminah, dirigiéndose a la dinamizadora. Con respecto a la cuarta pregunta, propusieron realizar una tertulia sobre religión, como se anticipaba en el apartado anterior, puesto que era un tema que siempre se encontraba ligado transversalmente a sus valoraciones.

Precisamente, una vez concluida esta tertulia imprevista, tuvo lugar un nuevo y último grupo de intercambio de opinión a fin de conocer ciertas valoraciones finales de las participantes: ¿Cuál es el tema que más os ha gustado? ¿Y el que menos? ¿Os habéis sentido a gusto? ¿Os gustaría repetir esta experiencia?

A pesar de que al principio no se atrevían a decantarse por ningún tema, las participantes coincidieron finalmente en que el amor y la religión habían sido, sin duda, sus preferidos. Asimismo sus breves pero sinceras declaraciones confirmaron que se habían sentido muy a gusto: «tengo confianza para contar mis problemas... todo lo que me preocupa», expresó Odele; «amo los martes, podemos hablar», dijo por su parte Anisa, y Farah insistió en que «me gusta todo. Conocemos España y también podemos hablar de nuestro país». A su vez, todas ellas afirmaron que repetirían la experiencia encantadas.

Por otro lado, la elaboración de un diario de campo ha hecho posible la descripción con detalle del desarrollo de las tertulias y ha permitido el registro de observaciones, de las que se desprende una evolución muy positiva a lo largo del tiempo.

\section{Conclusiones}

A la luz de los resultados anteriores podemos concluir que Café y palabras ha alcanzado los objetivos que se habían propuesto inicialmente, a escala individual y grupal, así como ha traído consigo otras consecuencias positivas que han ido surgiendo espontáneamente de la interacción. 
En primer lugar, cabe destacar que el desarrollo de las sesiones se vio influido por la procedencia y, en especial, las creencias religiosas de las participantes, once de las cuales profesaban el Islam: estas mujeres, cuya religión restringe los ámbitos de relación entre amigas, encontraron en las tertulias un espacio para desinhibirse y exteriorizar sus inquietudes. A lo largo de las seis reuniones lloraron juntas, recordando la nostalgia de los seres queridos, pero principalmente compartieron decenas de alegrías y sonrisas, ruborizándose también en ocasiones, si alguna de ellas hablaba de sexo.

Esta experiencia contribuyó a que todas fortalecieran los lazos que hasta el momento les unían como compañeras de clase, y entablaran conversación con mujeres de nacionalidades distintas a las habituales. Otra señal más de que $\mathrm{Ca}$ fé y palabra» fue génesis de diversidad y enriquecimiento cultural es el protagonismo que ellas mismas otorgaron al aspecto culinario, convirtiéndose en un hábito que les ayudaba a sentirse cerca de sus raíces y les permitía ser embajadoras de su cultura. Como consecuencia de ello, la función que cumplían los platos no se limitaba a un componente nutritivo, sino que conectaba con las emociones de las participantes, quienes experimentaban la libertad de no ser juzgadas, la satisfacción de un trabajo que se valoraba y la alegría de vivir en una sociedad que, aunque les resulte ajena, las considera y se enriquece gracias a ellas.

Por otra parte, sobresale una preferencia clara de las participantes por las tertulias que care- cen de dinámicas u otras actividades preparadas de antemano; o lo que es lo mismo, se decantan por aquellas en las que la conversación va tejiéndose libremente a partir de la propuesta de un tema, como el amor y la religión. Justamente, de las intervenciones de las mujeres de creencia musulmana puede intuirse un estrecho arraigo y respeto a su cultura y la influencia de la fe en todas las esferas vitales. Sin embargo, albergan también otros intereses o sueños universales, que a la par que ayudan a romper los prejuicios en torno a la figura femenina en el Islam, configuran la distinta identidad de cada una: así, al igual que Irina aprecia las tardes de cine con sus hijos, Nur siente debilidad por las tendencias de la moda, Farah desearía recorrer todas las capitales europeas y Leila disfruta con la lectura de buen libro.

Para concluir, este ciclo de tertulias representó para muchas participantes uno de los escasos momentos de esparcimiento que se dedican a sí mismas, en compañía de sus iguales y lejos de las obligaciones de la vida cotidiana. Significó la apertura de una ventana a una realidad más amplia de la que antes conocían, en la que los prejuicios no encuentran cabida. Inventó un camino para combinar una de sus mayores aficiones, la cocina, con la expresión sincera de sus emociones. Y propició la construcción de un puente hacia el acercamiento y la comprensión mutua.

En definitiva, Café y palabras contribuyó al empoderamiento de las participantes, la creación $\mathrm{y}$ fortalecimiento de los vínculos existentes entre ellas y la ampliación de sus puntos de vista.

\section{Referencias bibliográficas}

Beltrán Cely W.M. (2007). La sociología de la religión: una revisión del estado del arte. Revista Creer y Poder hoy, 35-54.

Assemblee Nationale. (1994). Neutralité de l'enseignement public; port de signes ostentatoires dans les établiseements scolaires Circular Bayrou, del 20 de septiembre de 1994 Disponible en: $\mathrm{http} / /$ www.assemblee-nationale.fr/12/dossiers/documents-laicite/document-3.pdf

Del Olmo, N. (2003). Construcción de identidades colectivas entre inmigrantes: ¿interés, reconocimiento y/o refugio? REIS, 104. 29-56.

Giró Miranda, J. y Fernández Sáenz de Pipaón, A. (2004). Mujeres inmigrantes. Invisibilidad y práctica cotidiana. Logroño: Instituto de Estudios Riojanos.

Goicoechea Gaona, Mª .A. y Clavo Sebastián, $M^{\mathrm{a}}$ J. (coords.) (2012). Mujeres que miran a mujeres: la comunidad pakistaní. Logroño: Universidad de La Rioja.

Harris, M (1981). Introducción a la antropología general. Madrid: Alianza

Innerarity, C. (2005). La polémica sobre los símbolos religiosos en Francia. La laicidad republicana como principio de integración. REIS, 111, 139-162.

Ley Orgánica 4/2000, de 11 de enero, sobre Derechos y Libertades de los Extranjeros en España y su Integración Social. 
Pajares, M. (2004.) El velo islámico: mediación frente a prohibición. Diario El País de 13 de enero. Pérez-Díaz, V., Álvarez-Miranda, B. y González-Enríquez, C. (2001). España ante la inmigración. Madrid: Fundación La Caixa

Pérez González, N. (2007). Interculturalidad: ¿un ámbito de la mediación? Portularia, 8 (1-2).

Pérez Grande, $M^{\mathrm{a}}$. D. (2008). Mujeres inmigrantes: realidades, estereotipos y perspectivas educativas. Revista Española de Educación Comparada, 14.

Torres, F. (2002). La integración de los inmigrantes y algunos desafíos que nos plantea. En J. De Lucas y F. Torres (eds.), Inmigrantes, ¿cómo los tenemos? Algunos desafios y (malas) respuestas (pp. 49-73). Madrid: Ediciones Talasa. 